Running Head: The unique contribution of shame memories to psychopathology

\author{
Above and beyond emotional valence: \\ The unique contribution of the central and traumatic shame memories \\ to psychopathology vulnerability \\ Marcela Matos*, MSc., Ph.D. Student \\ José Pinto-Gouveia, M.D., Ph.D. \\ Cristiana Duarte, MSc., Ph.D. Student \\ CINEICC \\ University of Coimbra, Portugal \\ * Correspondence concerning this article should be addressed to: \\ Marcela Matos \\ CINEICC, Faculdade de Psicologia e Ciências da Educação, Universidade de Coimbra \\ Rua do Colégio Novo, Apartado 6153 \\ 3001-802 Coimbra, Portugal \\ Telefone: $(+351) 239851450$ \\ Fax: $(+351) 239851462$ \\ E-mail: marcela.s.matos@gmail.com (M. Matos)
}




\title{
Above and beyond emotional valence: \\ The unique contribution of the central and traumatic shame memories \\ to psychopathology vulnerability
}

\begin{abstract}
This paper explores whether shame memories have a distinct impact on emotional difficulties and psychopathology that goes beyond their negative emotional valence. Study $1(N=292)$ investigates the contribution of centrality of shame memory, in comparison to the centrality of fear and sadness memories, to explain the memory' traumatic impact, shame, depression, anxiety, stress, paranoid and dissociative symptoms. Study $2(N=192)$ explores the impact of shame traumatic memory on shame and depression, anxiety and stress symptoms, in comparison to fear and sadness traumatic memories. Both studies used undergraduate student samples.

Results showed that shame memories centrality and traumatic features had an independent contribution to current external and internal shame and distinct psychopathological symptoms, after controlling for the effect of fear and sadness centrality and traumatic qualities. Moreover, shame memories centrality and traumatic features were the best global predictors of external and internal shame and depressive symptoms. Centrality of shame memories was also the only significant predictor of paranoid ideation and dissociation. These results offer novel perspectives on the nature of shame and its relation to psychopathology, emphasizing the distinct role of shame memories in human functioning and suffering, which goes above and beyond its negative emotional valence.
\end{abstract}

Keywords: Emotional memories; Shame; Centrality of event theory; Traumatic memory; Psychopathology 


\section{INTRODUCTION}

Shame has long been acknowledged as one of the most damaging/harmful self-conscious emotions (Gilbert, 1998; Kaufman, 1989; Lewis, 1971; Nathanson, 1994; Tangney \& Dearing, 2002; Tracy, Robins \& Tangney, 2007). This is a socially-focused multifaceted emotion, which blends with primary emotions (e.g., anger, anxiety, disgust) and involves physiological, affective, cognitive, behavioural and social components. Shame is seen as a "private emotion" but is usually related to the experience of having negative aspects of the self exposed to others (Lewis, 1992, 2003). Thus, shame is primarily linked to the experience of the others feeling ridicule or contempt for various aspects of the self, although it also comprises negative self-evaluations. Shame is then about a sense of the self as inferior, undesirable, defective or powerless as seen by others and through one's own eyes (Gilbert, 1998, 2007; Tangney \& Fisher, 1995; Tracy \& Robins, 2004).

The current study explores the uniqueness of shame memories to general psychopathology through the lens of an evolutionary biopsychosocial approach to shame (Gilbert, 1998, 2002, 2007). This model suggests that humans are a highly social species, whose survival and reproductive opportunities rely on how they relate to others and how others relate to the self. Throughout our lives, social relationships influence physiological and psychological regulation (Cozolino, 2006; Gerhardt, 2004; Schore, 1994). Hence, a suite of social motivational systems evolved to direct us towards forming and enacting certain types of social relationships and roles (e.g., as a friends, lovers, employees, team members) and to understand and think about the nature of our self-to-self and self-to-others relationships. Such systems incorporate innate motives to form and respond to attachment to carers (Bowlby, 1969/1982, 1973; Cassidy \& Shaver, 1999) and groups (Baumeister \& Leary, 1995), and concern with one's relative social place (Gilbert, 1992, 2000a, 2000b). Additionally, various cognitive competencies for self-conscious awareness (Tracy \& Robins, 2004; Lewis, 2003) and for social understanding (Byrne, 1995; Gilbert, 2007; Liotti \& Gilbert, 2011), matured to make us sensitive and responsive to how we exist in the minds of the others, i.e, what 
they think and feel about us. According to this view, evolution has, therefore, shaped us to be highly motivated to create positive affect in the mind of others, and to be seen as a socially attractive agent. In this sense, it is argued that when we achieve this, a sense of self as lovable and valued, and of the others as supportive and nurturing, is strengthened, and this creates a sense of safeness in the social domain (Baldwin, 1992, 1997; Gilbert, 1989, 1997, 2005; Mikulincer \& Shaver, 2005).

In contrast, the experience of shame seems to be a warning of perceived (real or imagined) threat or loss of abilities to create desirable images in the mind of the others, or lack of positive qualities others value, so that they may reject, harm, attack, or marginalize the self, placing one in an unwanted social rank position (Gilbert, 1998, 2002, 2007). When we feel we are not valued positively in the mind of the others and that they see us with negative affect (e.g., with contempt, criticism), this might activate what Gilbert (1997, 1998, 2003) defined as external shame. In external shame, our attention, thoughts and affects are focused in the mind of the other, and it is related to beliefs that they see us as unattractive or defective. This experience of the other as a threat to self and self-identity may trigger externalizing (e.g., aggression) or internalizing (e.g., submissive withdrawing) defensive strategies in order to keep the self safe. Internalized shame is one of these defenses and occurs when we identify with the mind of the other and engage in self-devaluation and self-blame (Gilbert, 1998, 2003). Our attention is directed inwardly to the inner landscapes (feelings and thoughts) of the self. Internal shame is then based on a sense of self as flawed and inadequate (Tangney \& Dearing, 2002), of becoming an undesired and unattractive self (Gilbert, 1998, 2003; Lindsay-Hartz, de Riviera \& Mascolo, 1995). Along with these self-evaluations and selfmonitoring, shame responses within social interactions often entail a desire to hide or conceal deficiencies and other forms of submissive-like defenses, such as changes in non-verbal behaviour, avoidance, appeasing others, in an effort to try to positively influence our image in their eyes and limit damage to our social position (Gilbert, 1998; Keltner \& Harker, 1998). 
Memories of shame experiences can understood in light of current conceptualizations of shame autobiographical memory (Berntsen \& Rubin, 2006, 2007). In particular, early experiences of shame, which unfold within our interactions with others, where a child experiences the emotions of others being directed at himself/herself, can lay down negative emotional memories and become the basis for self-experience and negative self-evaluations. Hence, shame experiences can be recorded in autobiographical memory, shaping one's global sense of self. In fact, empirical evidence suggests that shame recollections from childhood and adolescence can become a central component of personal identity, a turning point in the life story and a reference point for attribution of meaning to other events (Matos \& Pinto-Gouveia, 2011a, 2011b; Pinto-Gouveia \& Matos, 2011). These findings support the centrality of event theory (Berntsen \& Rubin, 2006, 2007), according to which a memory of a trauma or a negative emotional event can become central to one's life story and identity. Higher centrality of a negative or traumatic event have been related to increased levels of posttraumatic stress reactions, depression, anxiety, and dissociation, and worse physical health (Berntsen \& Rubin, 2006, 2007; Berntsen, Rubin \& Siegler, 2011; Boals, 2010; Boals \& Schuettler, 2011).

There has been growing evidence that shame memories, construed as key to one's identity and life story, tend to be highly accessible and psychologically harmful, translating into traumatic stress reactions and heightened feelings of shame in adulthood (Pinto-Gouveia \& Matos, 2011). In addition, centrality of shame memories was found to be related to elevated levels of depression, anxiety, stress, and paranoid symptoms, even when current shame feelings were controlled for, and to increase the impact of external and internal shame on depressive symptoms (Matos \& PintoGouveia, 2011a, 2011b; Pinto-Gouveia \& Matos, 2011). In other words, shame memories, which anchor our conceptions of ourselves and give meaning to our life narratives, seem to operate as selfdefining memories in the self-memory system (Conway, 2005, Conway \& Pleydell-Pearce, 2000; Pinto-Gouveia \& Matos, 2011; Singer \& Salovey, 1993). They seem to be interconnected with other 
memories and information in the cognitive networks of a person, forming a highly available reference point that colors the organization of autobiographical knowledge and guides attentional, emotional, and cognitive processing (Bernsten \& Rubin, 2006, 2007). In fact, and in light of autobiographical memory conceptualizations (e.g., Bluck, 2003; Bluck, Alea, Habermas, \& Rubin, 2005; Pillemer, 1998; Rasmussen \& Berntsen, 2009), shame memories seem to serve distinct selfrelated functions: self (self-identity, self-concept and self-continuity), social (maintain and nurture social bonds), and directive (instrumental and guide behavior) (Matos, Pinto-Gouveia, \& Gilbert, 2011).

In addition, as aforementioned, shame involves a primary threat to the (social) self. As a result, shame memories can operate as threat memories, like mini-scenes or emotional hotspots in the mind (Gilbert, 2003, 2007; Kaufman, 1989) and have strong emotional effects on self-schema with potential to create intrusions (Baumeister, Bratslavsky, Finkenauer, \& Vohs, 2001). Supporting this view, Matos and Pinto-Gouveia (2010) found that early shame experiences reveal traumatic memory characteristics, with intrusion, avoidance, and hyperarousal symptoms. Furthermore research has shown that shame traumatic memories have an impact on feelings of shame in adulthood and also amplify the impact of shame on depression (Matos \& Pinto-Gouveia, 2010, 2011a). Besides, these trauma memories were found to be associated with paranoid symptoms (Matos, Pinto-Gouveia, \& Gilbert, 2011) and linked to maladaptive emotion regulation processes, such as dissociation, rumination and thought suppression (Matos, Pinto-Gouveia, \& Costa, 2011).

Other theoretical and empirical accounts have explored the role of shame in the context of post-traumatic stress disorder (PTSD), and found shame to be a relevant emotion with an impact on the onset and maintenance of PTSD symptoms (Andrews, Brewin, Rose, \& Kirk, 2000; Brewin, Andrews \& Rose, 2000; Holmes, Grey, \& Young, 2005; Robignaugh \& McNally, 2010), underlying peri-traumatic and posttraumatic experiences of threats to the social self (for a review see Budden, 2009). A possible explanation for these findings may be found in recent 
conceptualizations of PTSD (Ehlers \& Clark, 2000) and shame-based PTSD (Budden, 2009; Harman \& Lee, 2010; Lee, Scragg, \& Turner, 2001) in that shame might cause an ongoing threat to one's psychological integrity, leaving one to feel inferior, powerless or socially unattractive. Inherent in this proposition is the idea that post-traumatic symptoms may be generated and maintained by shame and not only by fear.

Although past research has demonstrated that the extent to which an early shame experience becomes central to one's identity and incorporates traumatic memory features, is associated with psychopathological indicators (Matos \& Pinto-Gouveia, 2010, 2011a, 2011b; Pinto-Gouveia \& Matos, 2011), it remains unclear whether shame memories have a unique effect on psychopathology or whether this effect is based solely on the negative emotionality beneath these shame experiences. One way to test this hypothesis is by comparing the impact of shame memories with the impact of other negative emotional events. Fear and sadness are two emotional experiences that are also known to be pervasive and linked to poorer mental health (e.g., depression, anxiety, PTSD, dissociation) (e.g., Boelen, 2009; Berntsen \& Rubin, 2007; Grey, Holmes, \& Brewin, 2001; Holmes et al., 2005).

On the other hand, current research on centrality of event and traumatic memory relied mainly on participants' recall of an undefined general event perceived as the most stressful or traumatic event in their lives (e.g., Berntsen \& Rubin, 2006; Boals, 2010; Boals, Steward, \& Schuettler, 2010; Newby \& Moulds, 2011; Rubin, Boals, \& Berntsen, 2008; Schuettler \& Boals, 2011; Thomsen \& Berntsen, 2009). Few studies primed participants with specific instructions on the type of emotional event to be recalled (e.g., shame; Matos \& Pinto-Gouveia, 2010; PintoGouveia, \& Matos, 2011), shame or guilt (Robinaugh \& McNally, 2010), sexual abuse (Robinaugh \& McNally, 2011), pain (Perri \& Keefe, 2008), or loss (Boelen, 2009). At the same time, research in PTSD literature has focused primarily on traumatic experiences involving fear, helplessness or horror, according to A1 and A2 criteria for PTSD diagnosis (Diagnostic and Statistical Manual of 
Mental Disorders, $4^{\text {th }}$ Edition, DSM-IV; American Psychiatric Association, 2000), with increasing studies highlighting the importance of investigating other emotions contained in traumatic memory and experiences (e.g., shame, anger, sadness) (Brewin, Andrews \& Rose, 2000; Grey et al., 2001; Harman \& Lee, 2010; Holmes et al., 2005). To date, no study has compared different types of emotional memories that become central and traumatic memories regarding their impact on psychopathology.

Therefore, the present study was designed to answer the following question: Is there any specificity in the way shame memories are related to psychopathology that differentiates them from other negative emotional memories, such as fear and sadness ones? Specifically, this research entails two major aims. The first is to explore the relative contribution of the centrality of shame memories to psychopathology vulnerability (i.e., traumatic stress reactions, shame, depression, anxiety, stress, dissociation, and paranoia), in comparison to the centrality of other negative emotional experiences, in particular fear and sadness. We predict that each emotional memory (e.g., centrality of shame memory) would be specifically associated with its traumatic impact (e.g., traumatic impact of the shame memory). Further, we hypothesize that shame memories, that come to be structured as key to self-identity and life story, would be independently associated with current external and internal shame and influence the experience of defeat and threat states, which could translate into depression, anxiety and stress symptoms. Also, given that shame memories are often about aversive interactions were others have been critical, rejecting or even harmful, it is quite possible that these memories become a source for suspiciousness, wariness and a paranoid orientation towards others in general and be linked to dissociative defenses, even after controlling for the centrality of fear and sadness memories. This first goal will be investigated in study 1 .

Secondly, study 2 explores the relative contribution of shame traumatic memories to shame feelings, and depression, anxiety and stress symptoms, in comparison to fear and sadness traumatic memories. Similarly to study 1 hypothesis, we expect that, when fear and sadness traumatic 
memories are controlled for, shame memories that reveal traumatic features would be uniquely linked to external and internal shame and to symptoms of depression, anxiety and stress.

\section{STUDY 1}

In Study 1, we explored the predictive qualities of centrality of shame memory against the centrality of other non shame negative emotional memories - fear and sadness - in regard to the traumatic impact of each emotional memory, external and internal shame, depression anxiety, stress, paranoid and dissociative symptoms.

\section{Method}

Participants

Participants in this study were 292 (259 women and 33 men) undergraduate students, recruited from University of Coimbra. Participants mean age was $22.01(S D=5.16)$, ranging from 18 to 50 , and the majority was single $(93.2 \%, n=272)$. Participants years of education mean was $14(D P=1.42)$. No gender differences were found concerning the variables under consideration.

\section{Measures}

Emotional memory centrality and traumatic features

Centrality of Event Scale (CES; Berntsen \& Rubin, 2006; Portuguese version by Matos, Pinto-Gouveia, \& Gomes, 2010) comprises 20 items, measuring the degree to which a memory of a stressful or traumatic event forms central component of a person's identity (e.g., "I feel that this event has become part of my identity."), a turning point in the life story of the person (e.g., "I feel that this event has become a central part of my life story.") and a reference point for the attribution of meaning to other events (e.g., "This event has coloured the way I think and feel about other experiences."). Participants are asked to rate the extent to which they agree with the statements 
from 1 (Totally disagree) to 5 (Totally agree). Participants completed three CES, one for each emotional memory: shame, fear and sadness (the detailed instructions for these emotional memories priming are given below). In its original study, CES reported a high internal consistency (Cronbach $\alpha=.94, .96)$. In the present studies, we also found CES (for shame, fear and sadness) to have an excellent internal consistency (Table 1).

Impact of Event Scale - Revised (IES-R; Weiss \& Marmar, 1997; Portuguese version by Matos, Pinto-Gouveia, \& Martins, 2010) is a self-report measure designed to assess current subjective distress and PTSD symptoms for any specific life event. It measures three aspects of traumatic stress reactions: avoidance (e.g., "I stayed away from reminders of it"), intrusion (e.g., "Any reminder brought back feelings about it") and hyperarousal (e.g., "I was jumpy and easily startled"), that parallel the DSM-IV criteria for PTSD. The IES-R has 22 items rated on a 5-point scale (0-4). In our study, participants completed the IES-R in regard to the shame, fear and sadness memory from childhood or adolescence (the same memory nominated for the CES scale, which detailed instructions are given below). In the original studies, the Cronbach $\alpha$ 's of the subscales range from .87 to .92 for intrusion, .84 to .86 for avoidance and .79 to .90 for hyperarousal. In our research, we found the IES-R (for shame, fear and sadness) to have high internal consistency (Table $1)$.

\section{Priming for the emotional memories}

Before completing the measures regarding each emotional memory variable, participants were given the following instructions to prime for shame, fear and sadness memories and answer the respective instruments measuring the centrality to personal identity of such memories and their traumatic memory characteristics.

Shame memory:

The experience of the emotion of shame is common to all humans. Everyone typically experiences several shame episodes throughout their lives. In this study we are interested in getting to know your shame experiences, that is, situations where you felt shame. 
By shame we mean the negative emotion associated with a sense of inferiority and personal devaluation. We feel shame when we judge ourselves in a particular situation (due to personal attributes or behavior) as inadequate, different, inferior, weak, repulsive, or globally bad, but also, when we feel others see us as inferior, defective, inadequate, weak or repulsive. When we feel shame, we might experience other emotions at the same time, such as anxiety, anger, or disgust, and we feel a string urge to hide, disappear, or run away.

Now, please try to recall a significant/stressful situation or experience where you think you felt shame, during childhood and/or adolescence. Please respond to the following items with this memory as your focus.

\section{Sadness memory:}

The experience of the emotion of sadness is frequent in all humans. Everyone typically experiences several sadness episodes throughout their lives. In this study we are interested in getting to know your sadness experiences, that is, situations where you felt sad.

By sadness we mean the negative emotion marked by feelings of loss, defeat, or powerlessness. When people feel sad, they often loose energy and drive, and the interest and pleasure for things.

Now, please try to recall a significant/stressful situation or experience where you think you felt sad, during childhood and/or adolescence. Please respond to the following items with this memory as your focus.

\section{Fear memory:}

The experience of the emotion of fear is frequent in all humans. Everyone typically experiences several fear episodes throughout their lives. In this study we are interested in getting to know your fear experiences, that is, situations where you felt frightened.

By fear we mean the negative emotional experience linked to the perception of a threat or danger to the self. This threat or danger might be real or imaginary and might entail threats to physical survival or to one's valuable life goals. When people feel frightened they often have fight, escape or avoidance behaviours.

Now, please try to recall a significant/stressful situation or experience where you think you felt frightened, during childhood and/or adolescence. Please respond to the following items with this memory as your focus.

\section{Shame}

Other As Shamer Scale (OAS) (Allan, Gilbert, \& Goss, 1994; Goss, Gilbert, \& Allan; 1994; Portuguese version by Matos, Pinto-Gouveia \& Duarte, 2011a) consists of 18 items measuring external shame (global judgements of how people think others view them). For example, respondents indicate the frequency on a 5 -point scale $(0=$ Never to $4=$ Almost always $)$ of their feelings and experiences to items such as, "I feel other people see me as not quite good enough" and "I think that other people look down on me". Higher scores on this scale reveal high external 
shame. In their study, Goss et al. (1994) found this scale to have a Cronbach's $\alpha$ of .92. In this study, the Cronbach's $\alpha$ was also high (Table 1).

Internalized Shame Scale (ISS) (Cook, 1994, 2001; Portuguese version by Matos, PintoGouveia, \& Duarte, 2011b) comprises a 24-item measure of internal shame, consisting of negatively worded items (e.g., "Compared with other people, I feel like I somehow never measure up") assessing the frequency in which people experience feelings of shame and a 6-item scale consisting of positively worded items (e.g., "All in all, I am inclined to feel that I am a success") assessing selfesteem. All of the items are rated on a scale of "0", meaning "never," to "4", meaning "almost always." The shame subscale items were based on phenomenological descriptions of shame feelings. In this study, only the shame subscale was used as a measure of internal shame. Previous studies (Cook, 1996) have reported test-retest correlations of .84 and .69, respectively, and have reported good convergent and divergent validity. The ISS shame subscale revealed an excellent internal consistency in both studies (Table 1).

\section{Psychopathology}

Depression, Anxiety and Stress Scale (DASS-42; Lovibond \& Lovibond, 1995; Portuguese version by Pais-Ribeiro, Honrado \& Leal, 2004) is a self-report measure composed of 42 items and designed to assess three dimensions of psychopathological symptoms: depression, anxiety and stress. The items indicate negative emotional symptoms and the respondents are asked to rate each item on a 4-point scale (0-3). On the original version, Lovibond and Lovibond (1995) found the subscales to have high internal consistency (Depression subscale Cronbach's $\alpha=.91$; Anxiety subscale Cronbach's $\alpha=.84$; Stress subscale Cronbach's $\alpha=.90$ ). In the present research, the three subscales also showed high internal consistency (Table1).

Paranoia Checklist (PC; Freeman et al., 2005; Portuguese translation and adaptation by Lopes \& Pinto-Gouveia, 2005). The PC was developed to investigate paranoid thoughts of a more 
clinical nature than those assessed in the GPS and to provide a multi-dimensional assessment of paranoid ideation. This checklist has 18 items that consist on thoughts that range from interpersonal sensitivities and social evaluative concerns related to social scrutiny to severe paranoid ideation (e.g., "Bad things are being sad about me behind my back", "I might be being observed or followed", "People would harm me if given an opportunity", "There is a possibility of a conspiracy against me"). Participants have to report the frequency of the thoughts, degree of conviction in them and distress caused by them in 5 point Likert scales (1-5). In its original study, this scale showed Cronbach alpha of .90 or more for each dimension. In study 1, the Cronbach alpha for Frequency, Conviction and Distress dimensions was high (Table 1).

Dissociative Experiences Scale - Revised (DES-II; Carlson \& Putnam, 1993, Portuguese translation and adaptation by Dinis, Matos, \& Pinto Gouveia, 2008) is the most widely used measure of dissociation and assesses the frequency of dissociative symptoms, such as amnesia, absorption, depersonalization and desrealization. The 28 items related to dissociative phenomena in daily life items are rated on a scale from $0 \%$ (never) to $100 \%$ (always), corresponding to the frequency in which those symptoms are experienced. Examples of such phenomena include feelings of depersonalisation, derealisation, and psychogenic amnesia. The DES-II produces scores very similar to those on the original version (Bernstein \& Putnam, 1986). In its original study, Cronbach's alpha was .90 (Carlson \& Putnam, 1993) and in study 1 of the present paper it revealed an excellent internal reliability (Table 1).

\section{Procedure}

Participants were given this series of self-report questionnaires, administered in the same order, at the end of a lecture after the consent of the educational institution board. In line with ethical requirements, before filling the measures it was emphasized that their co-operation was voluntary and their answers were confidential and only used for the purpose of the study. The series of 
measures took approximately 20 minutes to complete. In order to avoid overloading all participants with filling the total set of the self-report instruments described above, only 100 subjects of the total sample completed both the three CES and the three IES-R. These participants took 10 extra minutes to complete the measures.

\section{Data analysis}

Data analyses were conducted using PASW (Predictive Analysis Software) version 18 (SPSS Inc., Chicago, IL, USA). A within subjects design with repeated measures procedures was used to test the significance of mean differences between the study variables and Paired Samples $t$ Tests were conducted to make post-hoc comparisons. Pearson product-moment correlations were performed to explore the relationships among the emotional memories measures (CES_Shame, CES_Fear, CES_Sadness, in Study 1 and IES-R_Shame, IES-R_Fear, IES-R_Sadness in Study 2). A series of multiple regression analyses (using enter method) were performed using the abovementioned emotional memory measures of each study as independent variables to predict the dependent variables. This procedure will be explained in more detail along the two studies. Effects with $p<.050$ were considered statistically significant (Cohen, Cohen, West, \& Aiken, 2003; Tabachnick, \& Fidell, 2007).

\section{Results}

Descriptives

The descriptive statistics for this study are reported in Table 1. Results revealed that the means and standard deviations for the variables studied are similar to the ones found in prior studies using analogous samples (e.g., Berntsen \& Rubin, 2006, 2007; Goss, et al., 1994; Matos \& PintoGouveia, 2010; Matos, Pinto-Gouveia \& Costa, 2011; Matos, Pinto-Gouveia, \& Duarte, 2011a, 2011b; Matos, Pinto-Gouveia \& Gilbert, 2011; Pinto-Gouveia \& Matos, 2011). 
Results show that shame experiences do indeed reveal centrality of memory characteristics, as do fear and sadness memories. A within subjects design with repeated measures procedure was conducted to test the significance of the difference between these variables means (having as dependent variable the CES regarding the three types of emotional memory). There were significant differences between centrality of shame memory, centrality of fear memory and centrality of sadness memory, [Wilks' Lambda $\left.=.587, F_{(2,290)}=102.07, p<.001\right]$. Three Paired Samples T-Tests were used to make post-hoc comparisons. A first Paired Samples T-Test indicated that there was a significant difference in the scores of centrality of shame memory $(M=46.53, S D=17.07)$ and centrality of fear memory $(M=52.39, S D=18.67)$ variables $\left[t_{(291)}=5.58, p<.001\right]$. A second Paired Samples T-Test showed that there was a significant difference between centrality of shame memory $(M=46.53, S D=17.07)$ and centrality of sadness memory memories scores $(M=61.35$, $S D=17.93)\left[t_{(291)}=14.00, p<.001\right]$. And a third Paired Samples T-Test indicated that there was significant difference in the scores for centrality of fear memory $(M=52.39, S D=18.67)$ and centrality of sadness memory memories $(M=61.35, S D=17.93)$ variables $\left[t_{(291)}=9.20, p<.001\right]$.

(Table 1 about here)

\section{Correlations}

Pearson product-moment correlations were conducted to examine the associations between the variables (Table 2). Centrality of shame memory, as well as centrality of fear and sadness memories, were positively and significantly correlated with the traumatic impact of those memories, measures of external and internal shame, depression, anxiety, and stress, paranoid symptoms and dissociation (Table 2).

(Table 2 about here)

\section{Multiple regression analyses}


A series of multiple regression analyses were performed to investigate the specificity in the way the centrality of each emotional memory (independent variables) predicted its traumatic impact, external and internal shame, psychopathological symptoms, such as depression, anxiety and stress, paranoid symptoms and dissociation (dependent variables).

Centrality of shame, fear and sadness memories predicting their traumatic impact

Results revealed that the model using centrality of shame, fear and sadness memories to predict their traumatic impact accounted for $29 \%$ of the traumatic impact of the shame memory and centrality of shame memories emerged as the best global predictor. Regarding the traumatic impact of the fear memory, the model explained $39 \%$ of the variance and centrality of fear memories was found to be the best global predictor. Finally, $36 \%$ of the variance in traumatic impact of the sadness memory was accounted for this set of variables and centrality of sadness memories emerged as the best global predictor (see Table 3).

(Table 3 about here)

Centrality of shame, fear and sadness memories predicting shame

Table 4 presents multiple regression analysis results of centrality of shame, fear and sadness memories on the prediction of shame variables. Regarding external shame, this set of variables accounted for $22 \%$ of the variance, with centrality of shame memory emerging as the best global predictor followed by centrality of sadness memory. In terms of internal shame, the model accounted for $25 \%$ of the variance and centrality of shame memory was as the best global predictor, followed by centrality of sadness memory.

(Table 4 about here)

Centrality of shame, fear and sadness memories predicting psychopathology 
Table 5 presents the regression analysis results for centrality of shame, fear and sadness memories on psychopathology prediction. The first model accounted for $16 \%$ of depressive symptoms variance, with centrality of shame memories emerging as the best global predictor followed by centrality of sadness memories. In regard to anxiety, centrality of shame, fear and sadness memories explained $15 \%$ of variance in anxiety symptoms and centrality of fear memories emerged as the only significant global predictor. The third model accounted for $13 \%$ of stress symptoms variance. Centrality of shame memories and centrality of sadness emerged as the two significant predictors.

(Table 5 about here)

Centrality of shame, fear and sadness memories predicting paranoid symptoms and dissociation

In regard to paranoid symptoms (see Table 6), the regression analysis with centrality of shame, fear and sadness memories as independent variables reveals that model accounted for $10 \%$ of the variance in paranoid symptoms frequency, with centrality of shame memory emerging as the only significant global predictor. Furthermore, this set of variables accounted for $16 \%$ of paranoia distress variance and centrality of shame memory was the only significant predictor. No significant model was found in relation to paranoia conviction.

Concerning dissociative symptoms, centrality of shame, fear and sadness memories accounted for $13 \%$ of the variance, with centrality of shame memories emerging as the only significant global predictor (see Table 6).

(Table 6 about here)

\section{Discussion}

The results from Study 1 revealed that shame experiences do indeed reveal centrality of memory characteristics, as do fear and sadness memories. In fact, shame, fear and sadness 
memories significantly differ in the extent to which they are recalled as central to self-identity and life story, with sadness memories being the most central, followed by fear and shame memories. These data is consistent and extends Berntsen and Rubin (2006, 2007) model by suggesting that negative emotional memories impact on anchoring self-conceptions and structuring life narrative, is not undifferentiated but that distinct emotional memories may have different levels of centrality. Noteworthy, the current results demonstrated that memories in which shame was the most salient emotion also emerged as central to personal identity, following sadness and fear, the most frequently recognized as central emotional memories.

As expected, our findings indicated that there is specificity in the way the centrality of each emotional memory (e.g., centrality of shame, fear and sadness) predicts its traumatic impact (e.g., traumatic impact of shame, fear and sadness). These findings are in accordance with prior research (Pinto-Gouveia \& Matos, 2011) and uphold the centrality of event theory (Berntsen \& Rubin, 2006, 2007). They support the notion that when a negative emotional memory (e.g., of shame, fear, sadness) comes to be integrated as key to how one understands himself and the world, it forms a highly accessible and interconnected reference point to guide attention, emotion and cognitive processing, that thus can generate traumatic stress reactions. Besides, these findings add to the increasing amount of research showing that post-traumatic stress symptoms may derive from emotionally intense events that become central to identity and not necessarily from severe traumas that meet DSM criteria for PTSD (Berntsen, Ruben \& Siegler, 2011; Boals, 2010; Budden, 2009).

Our findings allowed us to establish that centrality of shame memories showed a unique and independent contribution to depression and stress prediction, even after the centrality of fear and sadness memories were controlled for. This means that shame memories are not just another form of negative affect. Instead, by representing a current threat to one's self-identity and social existence, they may be associated with triggering of defeat and threat states. 
Key in this study, was the finding that centrality of shame memories appeared as the best global predictor of current feelings of external and internal shame, and as the only predictor of dissociation and paranoia ideation frequency and distress, even when controlling for the centrality of fear and sadness memories. The same is to say that these central shame memories may lead one to develop a sense of self as inferior, unattractive and flawed in his own eyes and in those of the others and may render one more vulnerable to perceive others as holding malevolent intentions towards the self and to adopt dissociative defenses.

This corroborates our hypothesis and extends previous knowledge (Pinto-Gouveia \& Matos, 2011; Berntsen \& Rubin, 2006, 2007; Boals, 2010), establishing that shame memories that become a central component for a person's identity and self-understanding, a salient point in life story and a reference point to attribute meaning to other events, have a specific impact on psychopathological symptoms that goes above and beyond a general emotional negativity. In Study 2, we examine these relationships exploring the distinct effect of shame, fear and sadness traumatic memories on current shame feelings and psychopathological symptoms of depression, anxiety and stress.

\section{STUDY 2}

The purpose of Study 2 was to partially replicate the findings from the first study using the same emotional memories in relation to their traumatic features. Specifically, Study 2 investigated the relationships between shame traumatic memories and current feelings of external and internal shame, and depression, anxiety and stress symptoms, when controlling for the effect of fear and sadness traumatic memories.

\section{Method}

\section{Participants}


One hundred and ninety two undergraduate students (163 women and 29 men; mean age $24.79, S D=7.39)$ participated in this study. The majority was single $(83.9 \%, n=161)$ and participants presented a mean of $14.62(S D=1.62)$ years of education.

\section{Measures and procedure}

Participants completed the IES-R for the three emotional memories of shame, fear and sadness, the OAS, ISS and DASS-42, following the same methodological and statistical procedures described in Study 1.

\section{Results}

Descriptives

Table 1 presents the means and standard deviations for the variables studied, which presented similar scores to the ones found in previous studies using analogous samples (e.g., Goss et al., 1994; Matos \& Pinto-Gouveia, 2010; Matos, Pinto-Gouveia \& Gilbert, 2011; Matos, PintoGouveia \& Costa, 2011; Matos, Pinto-Gouveia, \& Duarte, 2011a, 2011b; Weiss \& Marmar, 1997).

Results show that shame episodes reveal traumatic memory characteristics, eliciting intrusion, hyperarousal and avoidance symptoms. Fear and sadness memories also present traumatic memory features. A within subjects design with repeated measure procedure was used to examine the significance of the difference between the mean scores of these variables (having as dependent variable the IES-R regarding the three types of emotional memory). There were significant differences between shame, fear and sadness traumatic memories, [Wilks' Lambda $=.786, F_{(2,190)}=$ 25.89, $p<.001]$. Post-hoc comparisons were conducted through three Paired Samples T-Tests. The first Paired Samples T-Test showed that there was a significant difference in the scores of shame traumatic memory $(M=4.49, S D=2.44)$ and fear traumatic memory $(M=4.94, S D=2.88)$ variables $\left[t_{(191)}=3.13, p<.010\right]$. A second Paired Samples T-Test indicated that there was a 
significant difference between shame traumatic memory $(M=4.49, S D=2.44)$ and sadness traumatic memory scores $(M=5.45, S D=2.86)\left[t_{(191)}=7.21, p<.001\right]$. The third Paired Samples T-Test showed that there was significant difference in the scores of fear traumatic memory $(M=$ 4.94, $S D=2.88)$ and sadness traumatic memory $(M=5.45, S D=2.86)$ variables $\left[t_{(191)}=3.62, p<\right.$ $.001]$

\section{Correlations}

Results from Pearson product-moment correlations (Table 2) show that shame, fear and sadness traumatic memories were positively and moderately associated with external and internal shame, and depressive, anxiety and stress symptoms.

\section{Multiple regression analyses}

In order to better understand the specificity of shame, fear and sadness traumatic memories (independent variables) as predictors of external and internal shame and psychopathological symptoms, such as depression, anxiety, and stress (dependent variables), a series of multiple regression analyses were carried out.

Shame, fear and sadness traumatic memories predicting shame

Multiple regression analyses results for shame, fear and sadness traumatic memories predicting shame variables are reported in Table 4. In regard to external shame, this set of variables accounted for $28 \%$ of the variance, with shame traumatic memory emerging as the only significant global predictor. The second model explained $36 \%$ of the variance in internal shame and shame traumatic memory was as the best global predictor, followed by fear traumatic memory.

Shame, fear and sadness traumatic memories predicting psychopathology 
Regression analysis results regarding psychopathology predicted by shame, fear and sadness traumatic memories (see Table 5), indicated that this set of variables accounted for $24 \%$ of depressive symptoms variance, with shame traumatic memory emerging as the only significant global predictor. Regarding anxiety, the model explained $28 \%$ of variance in anxiety symptoms and shame and fear traumatic memories were the significant global predictors. In relation to stress, $27 \%$ of the variance in stress symptoms was accounted for by the model and only sadness traumatic memory was a significant predictor.

\section{Discussion}

Overall, Study 2 findings supported the predictions in that shame memories with traumatic features of intrusion, avoidance and hyper arousal, were uniquely associated with external and internal shame and psychopathological symptoms, when fear and sadness traumatic memories were controlled for. In particular, the current data revealed that shame traumatic memories were the only predictor of external shame and had an independent effect on internal shame, along with fear traumatic memories. This implies that individuals whose shame experiences function as traumatic memories, tend to believe others see them negatively as unattractive or undesirable social agents. Moreover, it seems that such shame traumatic experiences can be internalized into negative selfevaluations and feelings, which combined with fear traumatic experiences, where one may have felt the self as powerless, weak or coward may give rise to the maturation of a self seen as inferior, incapable, defective - internal shame (Gilbert, 2003, 2007).

The relationship between shame traumatic memories and general psychopathology, when considering for other traumatic emotional memories, was also corroborated. Specifically, our findings indicate that shame traumatic memories were the only predictor of depressive symptoms whereas, surprisingly, sadness traumatic memories did not significantly account for depressive symptoms. Shame traumatic memories, along with fear traumatic memories, predicted anxiety. 
These results empirically contribute to recent conceptualizations of traumatic memory in the context of depression and PTSD (Brewin, Gregory, Lipton, \& Burgess, 2010; Brewin et al, 2000; Ehlers \& Clark, 2000; Lee et al, 2001; Holmes et al, 2005; Patel, Brewin, Wheatley, Wells, Fisher, \& Myers, 2007) suggesting that shame events that come to be structured as traumatic memories, eliciting intrusions, arousal symptoms and strong emotional avoidance, may colour our view of ourselves and the world and guide attention, thought and affect processing, representing a current threat to one's psychological integrity. This ongoing threat to the social self may then lead one to be locked in defeat and threat states, which, in turn, may explain the strong link of shame traumatic memories and depressive and anxiety symptoms.

In conclusion, the results from Study 2 were similar to Study 1 findings further supporting that shame memories that operate as traumatic ones have a distinct impact on mental well-being that overtakes the negative emotionality associated with shame experiences.

\section{GENERAL DISCUSSION}

A robust body of theoretical and empirical accounts have highlighted the importance of shame and shame memories on general human functioning and mental well-being (Gilbert, 1998, 2007; Matos \& Pinto-Gouveia, 2010, 2011a, 2011b; Pinto-Gouveia \& Matos, 2011; Tangney \& Dearing, 2002). Simultaneously, research on autobiographical and traumatic memory has focused on the relevance of emotional memories that become central to self-understanding and life narrative to psychological difficulties (Berntsen \& Rubin, 2006, 2007; Berntsen et al. 2011; Boals, 2010; Thomsen \& Berntsen, 2009). However, no research had yet examined whether there is specificity in the way shame memories structured as central and traumatic memories impact on psychopathology that exceeds the negative emotionality underlying these recollections. In the present paper, we have presented the first series of studies investigating the assumption that shame memories, central to one's identity and life story and with traumatic features, have an unique impact on psychopathology 
that goes beyond its negative emotional valence, differentiating them from other negative emotional memories, in this case, fear and sadness.

Across the two studies we have provided clear evidence showing that shame memories central to self-identity and traumatic have a distinct contribution to emotional difficulties and psychopathologies, when controlling for other types of emotional memories (fear and sadness). Our results confirm therefore that the effect of shame memories on psychopathology indicators overtakes the negative emotionality associated with shame experiences.

A possible explanation for these findings relies on the nature of shame itself. Shame is an emotion crucial to one's sense of self and self-identity as a social agent (Gilbert, 2007; Tangney \& Dearing, 2002; Tracy \& Robins, 2004). As postulated by the biopsychosocial approach (Gilbert, $1998,2002,2007)$, shame emerges in the context of one of the most threatening experiences for any human being: losing one's attractiveness in the eyes of the others because one holds negative qualities or lacks positive ones that other value. Hence, early shame experiences, where individuals felt they existed negatively on the minds of the other and evaluated themselves as sharing the same negative view, may become central in autobiographical memory. In other words, these shame memories may shape these individuals global sense of self, give meaning to past, present and future experiences, and structure their life narrative, thus fulfilling self, social and directive autobiographical memory functions (Bernsten \& Rubin, 2007; Bluck et al., 2005; Pillemer, 1998; Pinto-Gouveia \& Matos, 2011; Rasmussen \& Berntsen, 2009). By becoming highly available and linked to other autobiographical knowledge, they influence subsequent processing and may elicit intrusions, hyper arousal and avoidance symptoms. These traumatic features constantly place the shamed individual in face of an ongoing threat to the (social) self and his psychological integrity (Budden, 2009; Ehlers \& Clark, 2000; Harman \& Lee, 2010). Thus, these shame memories seem to have a long lasting effect by elevating current feelings of externally and internally focused shame and increasing vulnerability to enter defeat and threat states, translated into depressive, anxiety and 
stress symptoms. Also, central shame memories can become a source for distrust, suspiciousness, wariness and a paranoid orientation towards others in general, i.e., paranoid symptoms, and for engaging in maladaptive processes to regulate shame, e.g., dissociative symptoms.

Regarding fear and sadness memories, as expected, our study suggests that traumatic and central memories of fear are associated with anxiety symptoms, and sadness memories central to selfidentity are significant predictors of depressive symptoms, when other emotional memories are considered simultaneously. Interestingly, sadness memories' traumatic features were only associated with stress, and not depression, when the other emotional memories were controlled for. A possible explanation for this intriguing finding might be related to the instructions priming for the sadness memory, in which sadness was described as a "negative emotion defined by feelings of loss, defeat or powerlessness". Hence, sadness events involving some kind of loss or defeat might elicit increased negative affect and despair emotional states, which could be linked to stress symptoms. Even so, future research could investigate this hypothesis, for instance, controlling for the type of sadness memory participants recall.

The findings from the current research add further support to our previous work on the key role shame memories play in psychopathology (Matos \& Pinto-Gouveia, 2010, 2011a, 2011b; PintoGouveia \& Matos, 2011; Matos, Pinto-Gouveia, \& Costa, 2011). Shame memories do indeed independently contribute to understand psychopathology over and above other negative emotional memories. In addition, these data have implications for theories on autobiographical and traumatic memory and for clinical interventions, implying the uniqueness of shame traumatic central memories to understand a wide range of emotional and psychological difficulties. In fact, although different types of emotional memories are important to the development and maintenance of psychopathology, it seems that they are not all the same. Specifically, more important than a general negative emotional memory, it is when such emotional memory has implications to the kind of self I am that it becomes key to psychological functioning and suffering. So, in a therapeutic context, 
shame memories should be specifically evaluated and addressed (Gilbert, 2009, 2010; Matos \& Pinto-Gouveia, 2010, 2011a; Pinto-Gouveia \& Matos, 2011; Matos, Pinto-Gouveia \& Costa, 2011c; Matos, Pinto-Gouveia \& Duarte, 2011c).

These conclusions are constrained by some limitations. First, they cannot be generalized to other populations because our sample is a mainly female student sample. In the future, research should seek to replicate these findings in more heterogeneous and representative samples from the general community population and in clinical samples. Also the cross-sectional design used here precludes causal conclusions to be drawn from our results. This is an important issue future research could address through, for instance, prospective studies. Furthermore, the fact that participants were not randomly assigned to different sequences of emotional memories priming may have influenced our results. Nevertheless, insofar as all emotions primed may elicit global negative affectivity, the emotional activation following the prime of a particular memory might influence the recall of the others regardless of the order they are primed. This is an important issue for future research.

Nonetheless, we have presented novel research investigating the uniqueness of shame central and traumatic memories to psychopathology vulnerability, relatively to other emotional memories. Our findings offer consistent evidence emphasizing that the distinct contribute of shame memories to understand human functioning and suffering goes above and beyond their negative emotional valence.

\section{ACKNOWLEDGMENTS}

This research has been supported by the first author (Marcela Matos) Ph.D. grant number SFRH/BD/36617/2007, sponsored by FCT (Portuguese Foundation for Science and Technology). 


\section{REFERENCES}

Andrews, B., Brewin, C.R., Rose, S., \& Kirk, M. (2000). Predicting PTSD symptoms in victims of violent crime: The role of shame, anger and childhood abuse. Journal of Abnormal Psychology, 109, 69-73.

Baldwin, M.W. (1992). Relational schemas and the processing of social information. Psychological Bulletin, 112, $461-484$.

Baldwin, M. W. (1997). Relational schemas as a source of if-then self-inference procedures. Review of General Psychology, 1, 326-335.

Baumeister, R.F., Bratslavsky, E., Finkenauer, C., \& Vohs, K.D. (2001). Bad is stronger than good. Review of General Psychology, 5, 323-370.

Baumeister, R.F. \& Leary, M.R. (1995). The need to belong: Desire for interpersonal attachments as a fundamental human motivation. Psychological Bulletin, 117, 497-529.

Berntsen, D., \& Rubin, D. C. (2006). Centrality of Event Scale: A measure of integrating a trauma into one's identity and its relation to post-traumatic stress disorder symptoms. Behaviour Research and Therapy, 44, 219-231.

Berntsen, D., \& Rubin, D. C. (2007). When a trauma becomes a key to identity: Enhanced integration of trauma memories predicts posttraumatic stress disorder symptoms. Applied Cognitive Psychology, 21, 417-431.

Berntsen, D., Rubin, D.C., \& Siegler, I.C. (2011). Two versions of life: Emotionally negative and positive life events have different roles in the organization of life story and identity. Emotion, 11(5), 1190-1201. doi: 10.1037/a0024940.

Bluck, S. (2003). Autobiographical memory: Exploring its functions in everyday life'. Memory, 11(2),113-123.

Bluck S., Alea N., Habermas T., \& Rubin D.C. (2005). A tale of three functions: The self-reported uses of autobiographical memory. Social Cognition, 23, 91-117. 
Boals, A. (2010). Autobiographical memories that have become central to identity: Gender differences in the Centrality of Events Scale for positive and negative events. Applied Cognitive Psychology, 24, 107-121.

Boals, A. \& Schuettler, D. (2011). A double-edged sword: The relationship between event centrality, PTSD, and posttraumatic growth. Applied Cognitive Psychology, 25, 817-822.

Boals, A., Steward, J.M.**, \& Schuettler, D. (2010). Advancing our understanding of posttraumatic growth by considering event centrality. Journal of Loss and Trauma, 15, 518-533.

Boelen, P.A. (2009). The centrality of a loss and its role in emotional problems among bereaved people. Behaviour Research and Therapy, 47, 616-622.

Bowlby, J. (1969/1982). Attachment and loss, Vol. 1: Attachment. London: Hogarth Press.

Bowlby, J. (1973). Attachment and loss, Vol. 2: Separation. London: Hogarth Press.

Brewin, C.R., Andrews, B., \& Rose, S. (2000). Fear, helplessness and horror in posttraumatic stress disorder: Investigating DSM-IV Criterion 2A in victims of violent crime. Journal of Traumatic Stress, 13, 499-509.

Brewin, C., Gregory, J., Lipton, M., \& Burgess, N. (2010) Intrusive Images in Psychological Disorders: Characteristics, Neural Mechanisms, and Treatment Implications. Psychological Review. 117(1), 210-232.

Budden, A. (2009). The role of shame in posttraumatic stress disorder: A proposal for a socio-emotional model for DSM-V. Social Science and Medicine, 69, 1032-1039.

Byrne, R. W. (1995). The thinking ape. Oxford: Oxford University Press.

Carlson, B. E., \& Putnam, F. W. (1993). An update on the Dissociative Experiences Scale. Dissociation, 6, 16-27.

Cassidy, J \& Shaver, P.R (Eds.) (1999). Handbook of Attachment: Theory, Research and Clinical Applications (pp. 115-140). New York: Guilford Press.

Conway, M.A. (2005). Memory and the self. Journal of Memory and Language, 53, 594-628. 
Conway, M.A., \& Pleydell-Pearce, C.W. (2000). The construction of autobiographical memories in the self-memory system. Psychological Review, 107, 261-288.

Cook, D. R. (1994, 2001). Internalized shame scale: Technical manual. North Tonawanda, NY: Multi-Health Systems, Inc.

Cozolino, L. (2006). The Neuroscience of human relationships: Attachment and the developing brain. New York: Norton.

Dinis, A., Matos, M. \& Pinto-Gouveia, J. (2008). Portuguese translation and adaptation of the Dissociative Experiences Questionnaire: DES-II. Unpublished manuscript.

Ehlers, A. \& Clark, D. (2000). A cognitive model of posttraumatic stress disorder. Behaviour Research and Therapy, 38 (4), 319-345. doi:10.1016/S0005-7967(99)00123-0.

Freeman, D., Garety, P. A., Bebbington, P.E., Smith, B., Rollinson, R., Fowler, D., Kuipers, E., Ray, K. \& Dunn, G. (2005). Psychological investigation of the structure of paranoia in a nonclinical population. British Journal of Psychiatry, 186, 427-435.Gerhardt, S. (2004). Why love matters. How affection shapes a baby's brain. London: Bruner-Routledge.

Gilbert, P. (1989). Human nature and suffering. Hove: Lawrence Erlbaum Associates.

Gilbert, P. (1992). Depression: The Evolution of Powerlessness. London: Lawrence Erlbaum Associates.

Gilbert, P. (1997). The evolution of social attractiveness and its role in shame, humiliation, guilt and therapy. British Journal of Medical Psychology, 70, 113-147.

Gilbert, P. (1998). What Is Shame? Some Core Issues and Controversies. In P. Gilbert and B. Andrews (Eds.). Shame: Interpersonal Behaviour, Psychopathology and Culture (pp. 3-36). New York: Oxford University Press.

Gilbert, P. (2000a). Social mentalities: internal 'social' conflicts and the role of inner warmth and compassion in cognitive therapy. In P. Gilbert \& K.G. Bailey (Eds.), Genes on the Couch: Explorations in Evolutionary Psychotherapy (pp. 118-150). Philadelphia: Brunner-Routledge. 
Gilbert, P. (2000b). The relationship of shame, social anxiety and depression: the role of the evaluation of social rank. Clinical Psychology and Psychotherapy, 7, 174-189.

Gilbert, P. (2002). Body Shame: A Biopsychosocial Conceptualisation and Overview, with Treatment Implications. In P. Gilbert \& J. Miles (Eds.). Body Shame: Conceptualisation, Research and Treatment (pp. 3-54). London: Brunner.

Gilbert, P. (2003). Evolution, Social Roles and the Differences in Shame and Guilt. Social Research, 70, 1205-1230.

Gilbert, P. (2005). Social mentalities: A biopsychosocial and evolutionary reflection on social relationships. In, M.W. Baldwin (Ed.). Interpersonal Cognition. (pp. 299-335). New York: Guilford.

Gilbert, P. (2007). The evolution of shame as a marker for relationship security. In J.L. Tracy, R.W. Robins \& J.P. Tangney, (Eds.). The Self-Conscious Emotions: Theory and Research. (pp. 283-309). New York: Guilford.

Gilbert, P. (2009). The Compassionate Mind: A New Approach to Life's Challenges. London: Constable-Robinson. Oaklands CA.: New Harbinger.

Gilbert, P. (2010). Compassion Focused Therapy: Distinctive Features. London: Routledge.

Goss, K., Gilbert, P., \& Allan, S. (1994). An exploration of shame measures I. The "Other as Shamer Scale". Personality and Individual Differences, 17, 713-717.

Grey, N., Holmes, E., \& Brewin, C.R. (2001). Peri-traumatic emotional 'hotspots' in traumatic memory: A case series of patients with posttraumatic stress disorder. Behavioural and Cognitive Psychotherapy, 29, 367-372.

Harman, R. \& Lee, D. (2010), The role of shame and self-critical thinking in the development and maintenance of current threat in post-traumatic stress disorder. Clinical Psychology \& Psychotherapy, 17, 13-24. doi: 10.1002/cpp.636 
Holmes, E.A., Grey, N., \& Young, K. (2005). Intrusive images and 'hotspots' of trauma memories in posttraumatic stress disorder. Journal of Behavior Therapy and Experimental Psychiatry, $36,3-17$.

Kaufman, G. (1989). The Psychology of Shame: Theory and Treatment of Shame-based Syndromes. New York: Springer.

Keltner, D., \& Harker, L.A. (1998). The forms and functions of the nonverbal signal of shame. In P. Gilbert \& B. Andrews (Eds.) Shame: Interpersonal Behavior, Psychopathology and Culture (pp. 75-98). Oxford University Press: New York.

Lee, D., Scragg, P., \& Turner, S. (2001). The role of shame and guilt in traumatic events: A clinical model of shame-based and guilt-based PTSD. British Journal of Medical Psychology, 74, 451-467.

Lewis, H. B. (1971). Shame and guilt in neurosis. New York: International Universities Press.

Lewis, M. (1992). Shame: The Exposed Self. New York: The Free Press.

Lewis, M. (2003). The role of the self in shame Social Research. An International Quarterly of the Social Sciences, 70, 1181-1204.

Lindsay-Hartz, J., de Rivera, J., \& Mascolo, M.F. (1995). Differentiating guilt and shame and their effects on motivations. In J.P. Tangney \& K.W. Fischer (Eds.), Self-conscious Emotions. The Psychology of Shame, Guilt, Embarrassment and Pride (pp. 274-300). New York, NY: Guilford Press.

Liotti, G. \& Gilbert, P. (2011). Mentalizing, motivation, and social mentalities: Theoretical considerations and implications for psychotherapy. Psychology and Psychotherapy: Theory, Research and Practice, 84, 9-25. doi: 10.1348/147608310X520094.

Lopes, B., \& Pinto-Gouveia, J. (2005). Portuguese version of the 'Paranoia Checklist'. Unpublished manuscript. 
Lovibond, P. \& Lovibond, H. (1995). The structure of negative emotional states: Comparison of the depression anxiety stress scales (DASS) with beck depressive and anxiety inventories. Behaviour Research and Therapy, 3, 335-343.

Matos, M., \& Pinto-Gouveia, J. (2010). Shame as a Traumatic Memory. Clinical Psychology and Psychotherapy, 17, 299-312. doi: 10.1002/cpp.659.

Matos, M., \& Pinto-Gouveia, J. (2011a). Shamed by a parent or by others: The role of attachment in shame memories relation to depression. Manuscript submitted for publication.

Matos, M., \& Pinto-Gouveia, J. (2011b). Shame memories that shape who we are: The moderator effect of between shame and depression. Manuscript submitted for publication.

Matos, M., Pinto-Gouveia, J., \& Costa, V. (2011). Understanding the importance of attachment in shame traumatic memory relation to depression: The impact of emotion regulation processes. Clinical Psychology and Psychotherapy. doi: 10.1002/cpp.786.

Matos, M., Pinto-Gouveia, J., \& Duarte, C. (2011a). Other as Shamer: Versão portuguesa e propriedades psicométricas de uma medida de vergonha externa. Manuscript submitted for publication.

Matos, M., Pinto-Gouveia, J., \& Duarte, C. (2011b). When I don't like myself: Psychometric properties of the Portuguese version of the Internalized Shame Scale. Spanish Journal of Psychology. (In press)

Matos, M., Pinto-Gouveia, J., \& Duarte, C. (2011c). Constructing a self protected against shame: The importance of warmth and safeness memories and feelings on the association between shame memories and depression. Manuscript submitted for publication.

Matos, M., Pinto-Gouveia, J., \& Gilbert, P. (2011). The effect of shame and shame memories on paranoid ideation and social anxiety. Clinical psychology and Psychotherapy (In press). 
Matos, M., Pinto-Gouveia, J., \& Gomes, P. (2010). A Centralidade das Experiências de Vergonha: Estudo das propriedades psicométricas da versão portuguesa da Escala da Centralidade do Acontecimento. Psicologia, XXIV, 73-95.

Matos, M., Pinto-Gouveia, J., \& Martins, S. (2010). Propriedades psicométricas da versão portuguesa da Escala do Impacto do Acontecimento-Revista (IES-R). Psychologica. (In press).

Mikulincer, M., \& Shaver, P. (2005). Mental representations of attachment security: theoretical foundations for a positive social psychology. In M. W. Baldwin (Ed.), Interpersonal cognition (pp. 233-266). New York: Guilford.

Nathanson, D. L. (1994). Shame and pride: Affect, sex, and the birth of the self. New York: W. W. Norton \& Company.

Newby,J.M. \& Moulds, M.L. (2011). Intrusive memories of negative events in depression: Is the centrality of the event important? Journal of behavior therapy and experimental psychiatry, 42(3), 277-283. doi: 10.1016/j.jbtep.2010.12.011.

Pais-Ribeiro, J., Honrado, A., \& Leal, I. (2004). Contribuição para o estudo da adaptação portuguesa das Escalas de Ansiedade Depressão e Stress de Lovibond e Lovibond. Psychologica, 36, 235-246.

Patel, T., Brewin, C. R., Wheatley, J., Wells, A., Fisher, P., \& Myers, S. (2007). Intrusive images and memories in major depression. Behaviour Research and Therapy, 45, 2573-580.

Perri, C. M., \& Keefe, F. J. (2008). Applying Centrality of Event to Persistent Pain: A Preliminary Review. The Journal of Pain, 9, 265-271.

Pillemer, D. B. (1998). Momentous Events, Vivid Memories. Cambridge, MA: Harvard University Press.

Pinto-Gouveia, J. \& Matos, M. (2011). Can shame memories become a key to identity? The centrality of shame memories predicts psychopathology. Applied Cognitive Psychology, 25, 281-290. doi: 10.1002/acp1689. 
Rasmussen, A. S. \& Berntsen, D. (2009). The possible functions of involuntary autobiographical memories. Applied Cognitive Psychology, 23, 1137-1152. doi: 10.1002/acp.1615

Robinaugh, D. J., \& McNally, R. J. (2010). Autobiographical memory for shame or guilt events: Association with psychological symptoms. Behaviour Research and Therapy, 48, 646-652.

Robinaugh, D. J., \& McNally, R. J. (2011). Trauma centrality and PTSD symptom severity in adult survivors of childhood sexual abuse. Journal of Traumatic Stress, 24 (4), 483-6. doi: 10.1002/jts.20656.

Rubin, D. C., Boals, A., \& Berntsen, D. (2008). Memory in posttraumatic stress disorder: Properties of voluntary and involuntary, traumatic and non-traumatic autobiographical memories in people with and without PTSD symptoms. Journal of Experimental Psychology: General, $137,591-614$.

Schore, A.N. (2001). The effects of early relational trauma on right brain development, affect regulation, and infant mental health. Infant Mental Health Journal, 22, 201-269. doi:10.1002/1097-0355(200101/04)22:1<201::AID-IMHJ8>3.0.CO;2-9

Schuettler, D. \& Boals, A. (2011). The path to posttraumatic growth versus PTSD: Contributions of event centrality and coping. Journal of Loss and Trauma, 16, 180-194. doi: $10.1080 / 15325024.2010 .519273$

Singer, J. A., \& Salovey, P. (1993). The remembered self-Emotion and memory in personality. New York: The Free Press.

Tangney, J. P., \& Dearing, R. L. (2002). Shame and Guilt. New York: Guilford Press.

Tangney, J.P. \& Fischer, K.W. (Eds.) (1995). The Self-Conscious Emotions: Shame, Guilt, Embarrassment, and Pride. New York: Guilford Press.

Thomsen, D. K., \& Berntsen, D. (2009). The long-term impact of emotionally stressful events on memory characteristics and life story. Applied Cognitive Psychology, 23, 579-598. doi: 10.1002/acp.1495. 
Tracy, J.L., \& Robins, R.W (2004). Putting the self into self-conscious emotions: A theoretical model. Psychological Inquiry, 15, 103-125.

Tracy, J. L., Robins, R. W., \& Tangney J. P. (Eds.) (2007). The self conscious emotions: Theory and research. New York: Guilford Press.

Weiss, D. S., \& Marmar, C. R. (1997). The Impact of Event Scale - Revised. In J. P. Wilson, \& T. M. Keane (Eds.), Assessing Psychological trauma and PTSD (pp. 399-411). New York: Guilford Press. 
Table 1: Means $(M)$ standard deviations $(S D)$ and Cronbach' alpha for the self-report variables in Study 1 and Study 2

\begin{tabular}{|c|c|c|c|c|c|c|}
\hline \multirow[t]{2}{*}{ Variables } & \multicolumn{3}{|c|}{$\begin{array}{c}\text { Study } 1 \\
(N=292)\end{array}$} & \multicolumn{3}{|c|}{$\begin{array}{c}\text { Study } 2 \\
(N=192)\end{array}$} \\
\hline & $M$ & $S D$ & $\alpha$ & $M$ & $S D$ & $\alpha$ \\
\hline Centrality of shame memories (CES_Shame) & 46.53 & 17.07 & .96 & - & - & - \\
\hline Centrality of fear memories (CES_Fear) & 52.39 & 18.67 & .97 & - & - & - \\
\hline Centrality of sadness memories (CES_Sadness) & 61.35 & 17.93 & .96 & - & - & - \\
\hline Shame traumatic memory (IES-R_Shame) & 4.77 & 2.37 & .94 & 4.49 & 2.44 & .96 \\
\hline Fear traumatic memory (IES-R_Fear) & 5.04 & 2.82 & .94 & 4.94 & 2.88 & .95 \\
\hline Sadness traumatic memory (IES-R_Sadness) & 5.74 & 2.80 & .97 & 5.45 & 2.86 & .97 \\
\hline Depression (DASS) & 6.15 & 7.47 & .95 & 7.34 & 8.30 & .95 \\
\hline Anxiety (DASS) & 6.38 & 6.58 & .90 & 8.15 & 7.47 & .91 \\
\hline Stress (DASS) & 11.98 & 7.78 & .92 & 13.38 & 8.51 & .93 \\
\hline External shame (OAS) & 20.07 & 9.20 & .91 & 19.64 & 9.97 & .92 \\
\hline Internal shame (ISS) & 33.42 & 16.25 & .95 & 33.62 & 17.65 & .96 \\
\hline Dissociation (DES-II) & 18.88 & 12.49 & .93 & - & - & - \\
\hline Paranoia Frequency (PC_Freq) & 30.39 & 11.47 & .91 & - & - & - \\
\hline Paranoia Conviction (PC_Conv) & 35.59 & 14.62 & .96 & - & - & - \\
\hline Paranoia Distress (PC_Dist) & 22.01 & 16.13 & .97 & - & - & - \\
\hline
\end{tabular}


Table 2: Two-tailed Pearson correlations for Study $1\left(N=292^{1}\right)$ and Study $2(N=192)$

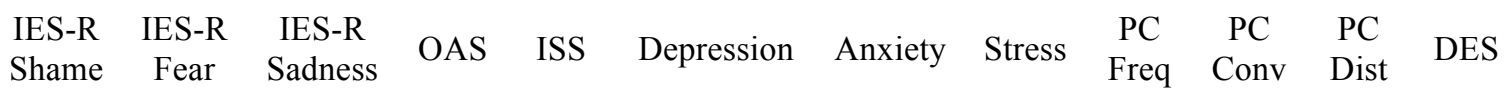

\begin{tabular}{|c|c|c|c|c|c|c|c|c|c|c|c|c|c|}
\hline \multirow{3}{*}{$\begin{array}{l}\text { Study } 1 \\
(N=292)\end{array}$} & $\begin{array}{c}\text { CES } \\
\text { Shame }\end{array}$ & $.45^{* *}$ & $.33 * *$ & $.36^{* *}$ & $.44 * *$ & $.45^{* *}$ & $.33 * *$ & $.28 * *$ & $.29 * *$ & $.29 * *$ & $.17^{*}$ & $.38 * *$ & $.32 * *$ \\
\hline & $\begin{array}{l}\text { CES } \\
\text { Fear }\end{array}$ & $.36^{* *}$ & $.54 * *$ & $.38 * *$ & $.34 * *$ & $.34 * *$ & $.31^{* *}$ & $.36^{* *}$ & $.28 * *$ & $.22 * *$ & $.20 * *$ & $.30 * *$ & $.28 * *$ \\
\hline & $\begin{array}{c}\text { CES } \\
\text { Sadness }\end{array}$ & $.33 * *$ & $.43 * *$ & $.47 * *$ & $.35^{* *}$ & $.40 * *$ & $.35 * *$ & $.29 * *$ & $.31 * *$ & $.26^{* *}$ & $.15^{*}$ & $.27 * *$ & $.28 * *$ \\
\hline \multirow{3}{*}{$\begin{array}{l}\text { Study } 2 \\
(N=192)\end{array}$} & $\begin{array}{l}\text { IES-R } \\
\text { Shame }\end{array}$ & - & - & - & $.51 * *$ & $.57 * *$ & $.46^{* *}$ & $.49 * *$ & $.46^{* *}$ & - & - & - & - \\
\hline & $\begin{array}{l}\text { IES-R } \\
\text { Fear }\end{array}$ & - & - & - & $.46^{* *}$ & $.55 * *$ & $.45 * *$ & $.49 * *$ & $.47 * *$ & - & - & - & - \\
\hline & $\begin{array}{c}\text { IES-R } \\
\text { Sadness }\end{array}$ & - & - & - & $.44 * *$ & $.52 * *$ & $.43 * *$ & $.46^{* *}$ & $.49 * *$ & - & - & - & - \\
\hline
\end{tabular}

Note. ${ }^{* *} p \leq .001: * p \leq .050$. CES_Shame $=$ Centrality of shame memory; CES_Fear $=$ Centrality of fear memory; CES_Sadness $=$

Centrality of sadness memory; IES-R_Shame = Shame traumatic memory; IES-R_Fear = Fear traumatic memory; IES-

R_Sadness = Sadness traumatic mermory; OAS = External Shame; ISS = Internal Shame; DES-II = Dissociation; PC Freq $=$ Paranoid ideation frequency; PC Conv = Paranoid ideation conviction; PC Dist $=$ Paranoid ideation distress.

${ }^{1}$ The $N$ of the correlations between CES and IES-R $n=100$. 
Table 3: Model summary and Beta values for multiple regressions for Study $1(N=100)$ having shame traumatic memory (IES-R_Shame), fear traumatic memory (IES-R_Fear) and sadness traumatic memory (IES-R_Sadness) as criterion variables

\begin{tabular}{|c|c|c|c|c|c|c|c|c|c|c|c|c|}
\hline & \multicolumn{4}{|c|}{$\begin{array}{l}\text { IES-R } \\
\text { Shame }\end{array}$} & \multicolumn{4}{|c|}{$\begin{array}{c}\text { IES-R } \\
\text { Fear }\end{array}$} & \multicolumn{4}{|c|}{$\begin{array}{c}\text { IES-R } \\
\text { Sadness }\end{array}$} \\
\hline & $\mathbf{R}$ & $\mathbf{R}^{2}$ & $\boldsymbol{F}$ & $\boldsymbol{\beta}$ & $\mathbf{R}$ & $\mathbf{R}^{2}$ & $\boldsymbol{F}$ & $\boldsymbol{\beta}$ & $\mathbf{R}$ & $\mathbf{R}^{2}$ & $\boldsymbol{F}$ & $\boldsymbol{\beta}$ \\
\hline Model & .54 & .29 & $26.19 * * *$ & & .63 & .39 & $40.20 * * *$ & & .60 & .36 & $34.42 * * *$ & \\
\hline CES_Shame & & & & $.32 * * *$ & & & & .03 & & & & .08 \\
\hline CES_Fear & & & & $.17^{*}$ & & & & $.49 * * *$ & & & & $.18^{*}$ \\
\hline CES_Sadness & & & & .15 & & & & $.17^{*}$ & & & & $.41 * * *$ \\
\hline
\end{tabular}

Note. $* * * p<.001 ; * * p<.010 ; * p<.050 . \beta=$ Standarized regression coefficient.

CES_Shame $=$ Centrality of shame memory; CES_Fear $=$ Centrality of fear memory; CES_Sadness $=$ Centrality of sadness memory. 
Table 4: Model summary and Beta values for the multiple regressions for Study $1(N=292)$ and Study $2(N=192)$ having external shame (OAS) and internal shame (ISS) as criterion variables

\begin{tabular}{|c|c|c|c|c|c|c|c|c|c|}
\hline & & \multicolumn{4}{|c|}{ OAS } & \multicolumn{4}{|c|}{ ISS } \\
\hline & & $\mathbf{R}$ & $\mathbf{R}^{2}$ & $F$ & $\beta$ & $\mathbf{R}$ & $\mathbf{R}^{2}$ & $F$ & $\beta$ \\
\hline \multirow{4}{*}{$\begin{array}{c}\text { Study } \\
1\end{array}$} & Model & .47 & .22 & $27.28 * * *$ & & .50 & .25 & $32.59 * * *$ & \\
\hline & CES_Shame & & & & $.32 * * *$ & & & & $.33 * * *$ \\
\hline & CES Fear & & & & .09 & & & & .04 \\
\hline & CES_Sadness & & & & $.14^{*}$ & & & & $.23 * * *$ \\
\hline \multirow{4}{*}{$\begin{array}{c}\text { Study } \\
2\end{array}$} & Model & .52 & .28 & $23.73 * * *$ & & .60 & .36 & $35.62 * * *$ & \\
\hline & IES-R_Shame & & & & $.36 * * *$ & & & & $.32 * * *$ \\
\hline & IES-R_Fear & & & & .17 & & & & $.23 *$ \\
\hline & IES-R Sadness & & & & .04 & & & & .10 \\
\hline
\end{tabular}

Note. ${ }^{* * *} p<.001 ; * * p<.010 ; * p<.050 . \beta=$ Standarized regression coefficient.

CES_Shame $=$ Centrality of shame memory; CES_Fear $=$ Centrality of fear memory; CES_Sadness $=$ Centrality of sadness memory; IES-R_Shame = Shame traumatic memory; IES-R_Fear = Fear traumatic memory; IES-

R_Sadness $=$ Sadness traumatic memory $;$ OAS $=$ External Shame; ISS $=$ Internal Shame. 
Table 5: Model summary and Beta values for the multiple regressions for Study $1(N=292)$ and Study $2(N=192)$ having depression, anxiety and stress (DASS-42) as criterion variables

\begin{tabular}{|c|c|c|c|c|c|c|c|c|c|c|c|c|c|}
\hline & & \multicolumn{4}{|c|}{ Depression } & \multicolumn{4}{|c|}{ Anxiety } & \multicolumn{4}{|c|}{ Stress } \\
\hline & & $\mathbf{R}$ & $\mathbf{R}^{2}$ & $F$ & $\beta$ & $\mathbf{R}$ & $\mathbf{R}^{2}$ & $\boldsymbol{F}$ & $\beta$ & $\mathbf{R}$ & $\mathbf{R}^{2}$ & $F$ & $\beta$ \\
\hline \multirow{4}{*}{$\begin{array}{c}\text { Study } \\
1\end{array}$} & Model & .40 & .16 & $18.45^{* * *}$ & & .39 & .15 & $16.89 * * *$ & & .36 & .13 & $14.15^{* * *}$ & \\
\hline & CES_Shame & & & & $.19 * *$ & & & & .11 & & & & $.16^{*}$ \\
\hline & CES_Fear & & & & .09 & & & & $.25 * * *$ & & & & .09 \\
\hline & CES_Sadness & & & & $.10 * *$ & & & & .09 & & & & $.18^{*}$ \\
\hline \multirow{4}{*}{$\begin{array}{c}\text { Study } \\
2\end{array}$} & Model & .49 & .24 & $19.70 * * *$ & & .53 & .28 & $24.44 * * *$ & & .52 & .27 & $22.99 * * *$ & \\
\hline & IES-R_Shame & & & & $.24 *$ & & & & $.25^{*}$ & & & & .13 \\
\hline & IES-R_Fear & & & & .21 & & & & $.24^{*}$ & & & & .19 \\
\hline & IES-R_Sadness & & & & .09 & & & & .09 & & & & $.24 *$ \\
\hline
\end{tabular}

Note. $* * * p<.001 ; * * p<.010 ; * p<.050 . \beta=$ Standarized regression coefficient.

CES_Shame $=$ Centrality of shame memory; CES_Fear = Centrality of fear memory; CES_Sadness $=$ Centrality of sadness memory; IESR_Shame $=$ Shame traumatic memory; IES-R_Fear $=$ Fear traumatic memory; IES-R_Sadness $=$ Sadness traumatic memory. 
Table 6: Model summary and Beta values for the multiple regressions for Study $1(N=292)$ having dissociation (DES-

II) and paranoia (PC Frequency, PC Conviction, PC Distress) as criterion variables

\begin{tabular}{|c|c|c|c|c|c|c|c|c|c|c|c|c|c|c|c|c|}
\hline & \multicolumn{4}{|c|}{ DES } & \multicolumn{4}{|c|}{ PC Frequency } & \multicolumn{4}{|c|}{ PC Conviction } & \multicolumn{4}{|c|}{ PC Distress } \\
\hline & $\mathbf{R}$ & $\mathbf{R}^{2}$ & $F$ & $\boldsymbol{\beta}$ & $\mathbf{R}$ & $\mathbf{R}^{2}$ & $F$ & $\beta$ & $\mathbf{R}$ & $\mathbf{R}^{2}$ & $\boldsymbol{F}$ & $\boldsymbol{\beta}$ & $\mathbf{R}$ & $\mathbf{R}^{2}$ & $\boldsymbol{F}$ & $\boldsymbol{\beta}$ \\
\hline Model & .36 & .13 & $14.31 * * *$ & & .31 & .10 & $9.38 * * *$ & & .21 & .05 & $4.20 * *$ & & .40 & .16 & $18.19 * * *$ & \\
\hline CES_Shame & & & & $.21 * * *$ & & & & $.23 * * *$ & & & & .09 & & & & $.29 * * *$ \\
\hline CES_Fear & & & & .11 & & & & .07 & & & & .14 & & & & .11 \\
\hline CES_Sadness & & & & .11 & & & & .06 & & & & .03 & & & & .02 \\
\hline
\end{tabular}

Note. $* * * p<.001 ; * * p<.010 ; * p<.050 . \beta=$ Standarized regression coefficient.

CES_Shame $=$ Centrality of shame memory; CES_Fear $=$ Centrality of fear memory CES_Sadness $=$ Centrality of sadness memory. 